\title{
Chemomechanical surface patterning and functionalization of silicon surfaces using an atomic force microscope
}

\author{
Brent A. Wascaser \\ Michael J. Maughan \\ Travis L. Niederhauser \\ Matthew R. Linford \\ Robert C. Davis
}

See next page for additional authors

Follow this and additional works at: https://scholarsarchive.byu.edu/facpub

Part of the Astrophysics and Astronomy Commons, and the Physics Commons

\section{Original Publication Citation}

Wacaser, Brent A., Michael J. Maughan, Ian A. Mowat, Travis L. Niederhauser, Matthew R. Linford, and Robert C. Davis."Chemomechanical surface patterning and functionalization of silicon surfaces using an atomic force microscope." Applied Physics Letters

\section{BYU ScholarsArchive Citation}

Wascaser, Brent A.; Maughan, Michael J.; Niederhauser, Travis L.; Linford, Matthew R.; Davis, Robert C.; and Mowat, Ian A., "Chemomechanical surface patterning and functionalization of silicon surfaces using an atomic force microscope" (2003). Faculty Publications. 514.

https://scholarsarchive.byu.edu/facpub/514 


\section{Authors}

Brent A. Wascaser, Michael J. Maughan, Travis L. Niederhauser, Matthew R. Linford, Robert C. Davis, and Ian A. Mowat 


\title{
Chemomechanical surface patterning and functionalization of silicon surfaces using an atomic force microscope
}

\author{
Brent A. Wacaser and Michael J. Maughan \\ Department of Physics and Astronomy, Brigham Young University, Provo, Utah 84602 \\ Ian A. Mowat \\ Charles Evans and Associates, 810 Kifer Road, Sunnyvale, California 94086-5203 \\ Travis L. Niederhauser and Matthew R. Linford ${ }^{\text {a) }}$ \\ Department of Chemistry and Biochemistry, Brigham Young University, Provo, Utah 84602 \\ Robert C. Davis ${ }^{\text {b) }}$ \\ Department of Physics and Astronomy, Brigham Young University, Provo, Utah 84602
}

(Received 17 June 2002; accepted 13 November 2002)

\begin{abstract}
Surface modification and patterning at the nanoscale is a frontier in science with significant possible applications in biomedical technology and nanoelectronics. Here we show that an atomic force microscope (AFM) can be employed to simultaneously pattern and functionalize hydrogen-terminated silicon (111) surfaces. The AFM probe was used to break $\mathrm{Si}-\mathrm{H}$ and $\mathrm{Si}-\mathrm{Si}$ bonds in the presence of reactive molecules, which covalently bonded to the scribed Si surface. Functionalized patches and patterned lines of molecules were produced. Linewidths down to $30 \mathrm{~nm}$ were made by varying the force at the tip. (C) 2003 American Institute of Physics.
\end{abstract}

[DOI: $10.1063 / 1.1535267]$

Nanoscale chemical patterning of molecular films on surfaces is an enabling technology with many attractive applications in nano- and biotechnologies. It has been demonstrated that chemical patterning can direct the placement of carbon nanotubes ${ }^{1}$ and plated metal films ${ }^{2}$ on surfaces to form electrical wire interconnects. These techniques can also direct the assembly of metallic and semiconductor nanocrystals on solid substrates for photonic and optical chemical sensing applications. ${ }^{3}$ Chemical patterns of bioactive molecules on surfaces have been developed for cellular adhesion and growth studies ${ }^{4}$ and are the basis of an increasing array of biosensor techniques, including commercial devices. ${ }^{5,6}$ These methods all rely on patterning and controlling chemical bonds at surfaces, thus allowing the chemical, molecular, and electrical properties of samples to be tailored.

A surface modification technique, chemomechanical surface functionalization, has recently been developed as a means of simultaneously chemically patterning and directing covalent bonding of molecules to silicon surfaces. ${ }^{7,8}$ When a hydrogen-terminated silicon surface is scribed, $\mathrm{Si}-\mathrm{Si}$ or $\mathrm{Si}-\mathrm{H}$ bonds are mechanically broken, producing a chemically active surface that reacts with a variety of molecules, covalently binding them directly to a crystalline silicon substrate. Chemomechanical surface functionalization is performed under ambient conditions and does not require a lithographic mask. Molecules including alkenes, alkynes, alkyl halides, alcohols, and carboxylic acids have been shown to react with scribed regions on silicon. Scribing native-oxide terminated silicon with a diamond scribe first produced monolayer-coated features with approximately 100 $\mu \mathrm{m}$ widths. ${ }^{7}$ Smaller features were scribed on hydrogenterminated silicon (111) substrates with a tungsten carbide

\footnotetext{
${ }^{a)}$ Electronic mail: mrlinford@chemdept.byu.edu

b)Electronic mail: davis@byu.edu
}

ball, producing linewidths as small as $20 \mu \mathrm{m} .{ }^{8}$

We report an extension of chemomechanical surface functionalization to even smaller features by using an atomic force microscope (AFM) to scribe a hydrogen-terminated silicon surface. This yields lines with widths down to $30 \mathrm{~nm}$. This technique employs an AFM fluid cell to immerse the AFM probe and silicon surface in a reactive liquid. The AFM uses tips that are much smaller than previous chemomechanical probes and gives improved force control. Thus surface damage can be minimized and feature size carefully controlled. Additionally in situ characterization can be performed with the same AFM tip used to create the features.

Several other nanoscale chemical patterning techniques have previously been developed, such as electron beam lithography, ${ }^{1,5}$ microcontact printing ${ }^{4,6}$ micromachining with a scalpel or carbon fiber, ${ }^{9}$ and AFM-based techniques. AFMbased methods include modification of self assembled monolayers by conductive $\mathrm{AFM},{ }^{1,3}$ dip pen nanolithography, ${ }^{10}$ nanoshaving monolayers on gold, ${ }^{11}$ and field enhanced oxidation of silicon followed by chemical modification of the oxidized patterns. ${ }^{12}$ Mechanical surface modification by AFM has also been applied to make oxidized patterns on silicon, ${ }^{13}$ but not to covalently bind molecules to surfaces. Chemomechanical surface patterning and functionalization using AFM is a technique that can potentially bind a variety of different molecules to a silicon surface. This technique does not require a mask and can be performed under ambient conditions.

The steps of chemomechanical surface functionalization with an AFM are: (1) preparing a hydrogen terminated silicon substrate, (2) wetting the surface with a reactive compound, (3) scribing the surface with an AFM probe, and (4) removing the unreacted compound. After scribing, the patterns were characterized by AFM, scanning electron microscopy (SEM), and time-of-flight secondary ion mass spectros- 
copy (TOF-SIMS). The preparations were all performed under ambient conditions without any special treatments or degassing of chemicals. A Digital Instruments (Santa Barbara, CA) Dimension 3100 AFM, equipped with a motorized optical microscope, a motorized stage, and a fluid cell was used for the AFM work.

Substrate Preparation-Si (111) chips were cleaned and etched to produce a hydrogen-terminated silicon surface. ${ }^{14}$ This was done by rinsing with acetone, drying with $\mathrm{N}_{2}$, immersing in $3: 7 \mathrm{H}_{2} \mathrm{O}_{2}: \mathrm{H}_{2} \mathrm{SO}_{4}$, for $10 \mathrm{~min}$ at $100-130^{\circ} \mathrm{C}$ to remove contaminants, rinsing for $\sim 1 \mathrm{~min}$ with Milli-Qwater and drying with $\mathrm{N}_{2}$. The chips were finally dipped in $40 \% \mathrm{NH}_{4} \mathrm{~F}$ for $7 \mathrm{~min}$ to remove the native oxide from the surface, rinsed for $\sim 10 \mathrm{~s}$ with Milli-Q-water, and blown dry with $\mathrm{N}_{2}$.

Wetting and scribing the surface-The surface was wet, in an AFM fluid cell, with a scribing liquid within an hour after the $\mathrm{NH}_{4} \mathrm{~F}$ etch. The scribing liquids, used as received were either $3,3,4,4,5,5,6,6,7,7,8,8,9,9,10,10,10$ heptadecafluoro-1-decene $\left(\mathrm{CF}_{3}\left(\mathrm{CF}_{2}\right)_{7} \mathrm{CH}=\mathrm{CH}_{2}\right), 99 \%$ (Aldrich), 1-hexadecene $\left(\mathrm{CH}_{3}\left(\mathrm{CH}_{2}\right)_{13} \mathrm{CH}=\mathrm{CH}_{2}\right), 92 \%$ (Aldrich), or 1-Octanol $\left(\mathrm{CH}_{3}\left(\mathrm{CH}_{2}\right)_{6} \mathrm{CH}_{2} \mathrm{OH}\right)$, Certified (Fisher Scientific). To scribe, the AFM tip was brought into contact with the surface with a set force and moved across the surface. Immediately after scribing, the chips were rinsed with ethanol ( $\sim 1 \mathrm{~min})$, then with Milli-Q-water $(\sim 1 \mathrm{~min})$, and blown dry with $\mathrm{N}_{2}$.

Force characterization - The force the tip exerts on the surface was determined using $F=-k z$, where $k$ is the spring constant of the cantilever and $z$ the vertical displacement. When scribing was performed under feedback control, $z$ was determined using $z=S \Delta V$, where $S$ is the AFM detector sensitivity and $\Delta V$ is the voltage difference between the set point voltage and the pre-engage vertical deflection voltage of the cantilever. We used high spring constant $(k$ $=23-91 \mathrm{~N} / \mathrm{m}$ ) silicon-based AFM tips coated with a $10 \mathrm{~nm}$ wear resistive silicon nitride coating, purchased from $\mu$ masch (Tallinn, Estonia). The spring constant of each cantilever was determined using $k=E w t^{3} / 2 l^{3}$, which incorporates the parallel beam approximation. ${ }^{15}$ The length $l$ and width $w$ of the cantilevers were defined lithographically to within 5\% variation, but the thickness $t$ of the cantilevers varied by $15 \%$. To obtain a more accurate cantilever thickness, the resonant frequency $f$ was measured and the thickness of the cantilever was determined using $t \approx 2 \pi f l^{2} \sqrt{\rho / E}$ were $\mathrm{E}$ and $\rho$ are the Young's modulus and density of silicon. ${ }^{16}$

Pattern characterization - Lines and patches were first characterized in situ by AFM with the same tip used to scribe them. The samples were then analyzed with a Philips (Hillsboro, OR) XL 30 S-FEG SEM with a low acceleration voltage $(1-5 \mathrm{kV})$. All images are secondary electron images taken with an annular through-the-lens detector. Patches scribed under $\mathrm{CF}_{3}\left(\mathrm{CF}_{2}\right)_{7} \mathrm{CH}=\mathrm{CH}_{2}$ were analyzed with a Physical Electronics (Eden Prairie, MN) TRIFT II TOFSIMS. Ion images were acquired in negative and positive ion modes using a primary ion beam potential of $28 \mathrm{kV}$ and a beam current of $600 \mathrm{pA}$. The beam size was $0.2 \mu \mathrm{m}$. Data were acquired over the mass range $m / z 5-m / z$ 1200, and the primary ion beam was rastered over a $75 \mu \mathrm{m}$ by $75 \mu \mathrm{m}$ area Downloaded 13 Feb 2009 to 128.187 .0 .164 . Redistribution subject

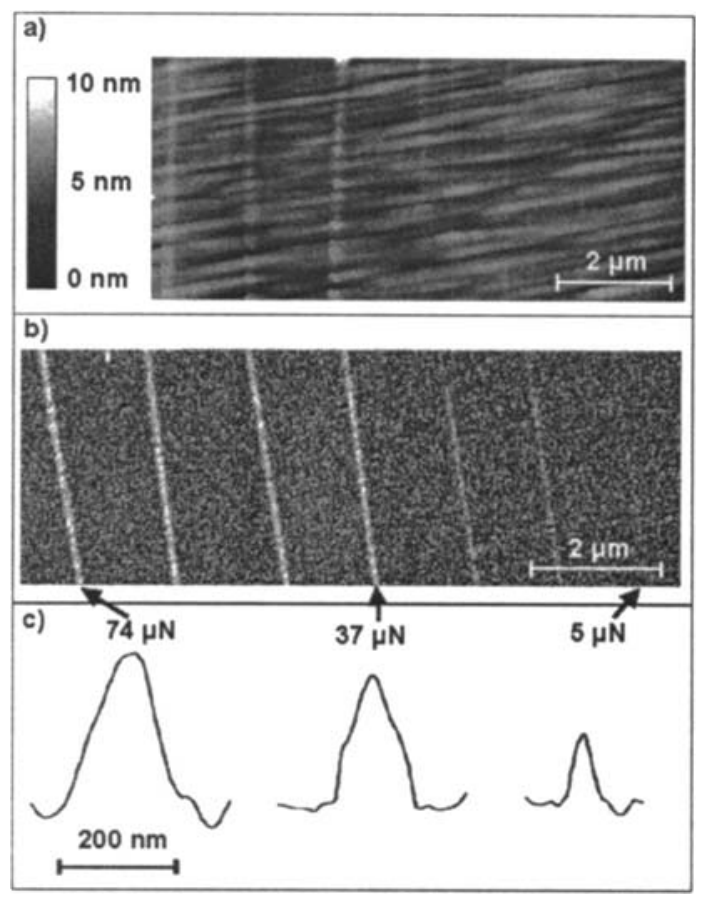

FIG. 1. (a) In situ AFM and (b) corresponding SEM images of seven lines scribed on silicon in the presence of $\mathrm{CF}_{3}\left(\mathrm{CF}_{2}\right)_{7} \mathrm{CH}=\mathrm{CH}_{2}$. Forces were, starting from the left, $74,62,49,37,25,12$, and $5 \mu \mathrm{N}$, and the tip speed was $10 \mu \mathrm{m} / \mathrm{s}$. (c) Profile plots of three of the lines in part (b). The arrows indicate the line that each of the plots were made from and the labels refer to the force used to scribe the lines. The vertical axis is the grayscale value.

to cover the areas patterned with the AFM. Ion images were acquired for a 4 min period from each patterned area.

Two major factors that control the dimensions of scribed lines are the force applied by the AFM tip and the tip shape. In Fig. 1 we show an AFM image, a SEM image, and profile plots derived from the SEM data of lines scribed on silicon while it was wet with $\mathrm{CF}_{3}\left(\mathrm{CF}_{2}\right)_{7} \mathrm{CH}=\mathrm{CH}_{2}$. These lines were patterned at various forces yielding wider lines at higher forces. By AFM, the five widest lines are discernable [Fig. 1(a)], but surface roughness $(1 \mathrm{~nm} \mathrm{rms})$ does not allow resolution of the finer lines. However, all seven of the lines can be resolved by SEM [Fig. 1(b)]. This contrast points to a difference in work function between scribed and unscribed regions on silicon. Linewidths were measured by taking the full width at half maximum of the profile plots [see Fig. 1(c)]. The line widths were $110 \mathrm{~nm}(74 \mu \mathrm{N}$ tip force), $85 \mathrm{~nm}$ (37 $\mu \mathrm{N}$ tip force), and $30 \mathrm{~nm}$ ( $5 \mu \mathrm{N}$ tip force). A comparison of the AFM and SEM images in Fig. 1 shows that the in situ AFM imaging of the patterns at a tip force of $0.25 \mu \mathrm{N}$ is nondestructive.

This technique is also able to produce complex patterns and filled areas. Figure 2 shows a pattern of the letters: BYU, along with a square functionalized patch. The letters are a good representation of the pattern with only slight deviations. The patch demonstrates the ability of this method to create larger functionalized features that are entirely filled in. To verify chemical functionalization of the patterned features, we analyzed scribed patches with TOF-SIMS. In its scanning mode this instrument acts as a chemical microscope. Figure 3(a) shows a TOF-SIMS image of the $\mathrm{F}^{-}$ion of a sample prepared by scribing rectangular patches on silicon that was wet with $\mathrm{CF}_{3}\left(\mathrm{CF}_{2}\right)_{7} \mathrm{CH}=\mathrm{CH}_{2}$. This image to AlP license or copyright; see http://apl.aip.org/apl/copyright.jsp 


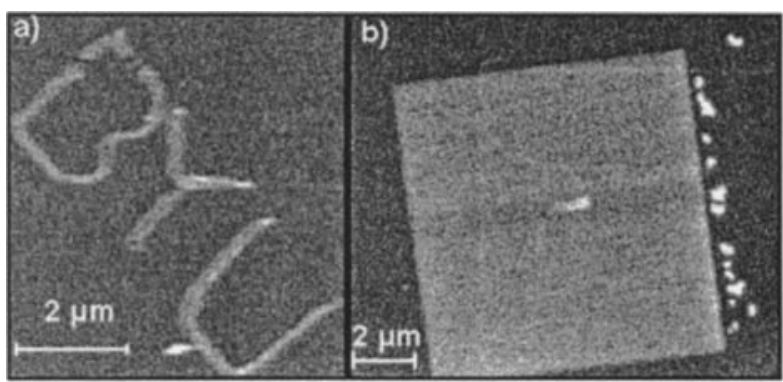

FIG. 2. SEM images of (a) a pattern of the letters BYU scribed in the presence of $\mathrm{CF}_{3}\left(\mathrm{CF}_{2}\right)_{7} \mathrm{CH}=\mathrm{CH}_{2}$ with a force of $93 \mu \mathrm{N}$ and a tip speed of $10 \mu \mathrm{m} / \mathrm{s}$. The letters in the pattern are $2.5 \mu \mathrm{m}$ long and the width of the lines is $\sim 400 \mathrm{~nm}$. (b) A patch scanned (scribed) three times in the presence of $\mathrm{CF}_{3}\left(\mathrm{CF}_{2}\right)_{7} \mathrm{CH}=\mathrm{CH}_{2}$ with a tip force of $14 \mu \mathrm{N}$. The scan size was $10 \mu \mathrm{m}$, the scan rate was $3 \mathrm{~Hz}$, and there were 256 lines per frame.

shows a clear enhancement of $\mathrm{F}^{-}$in the scribed regions over the unscribed background. It was anticipated that good ion yields would be obtained from $\mathrm{F}^{-}$because of fluorine's high electronegativity. There was also positive contrast between the scribed and unscribed regions in negative and positive spectra from $\mathrm{SiF}^{+}, \mathrm{SiF}^{-}, \mathrm{C}^{+}$, and $\mathrm{O}^{-}$. The $\mathrm{SiF}^{+}$and $\mathrm{SiF}^{-}$ ions may be the result of sputter-induced decomposition (followed by recombination) in the near-surface region. The $\mathrm{O}^{-}$ ion suggests that more oxidation of the silicon occurred in the scribed than unscribed regions. Oxidation of the silicon substrate following scribing was also observed in macroscopic scribing studies. ${ }^{11,12}$ Negative contrast, meaning that fewer ions were produced from the scribed regions, was observed in the $\mathrm{Si}^{+}$and $\mathrm{SiH}^{+}$images. These latter results are consistent with monolayer quantities of material covering the silicon substrate and removal of surface $\mathrm{Si}-\mathrm{H}$ moieties by scribing. Figure 3 also contains a SEM image of the same array of patches to demonstrate that the SEM contrast is consistent with the functionality of the regions as determined by TOF-SIMS. The variation in contrast of the patches in the SEM images is due to the fact that the AFM tip passed

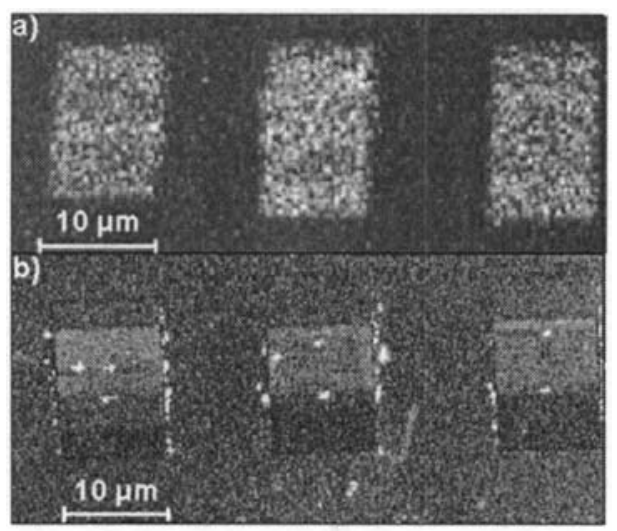

FIG. 3. (a) A TOF-SIMS image of the $\mathrm{F}^{-}$ion and (b) a SEM image of the same array of patches produced by scribing in the presence of $\mathrm{CF}_{3}\left(\mathrm{CF}_{2}\right)_{7} \mathrm{CH}=\mathrm{CH}_{2}$ with a force of $13 \mu \mathrm{N}$, a scan size of $10 \mu \mathrm{m}$, a scan rate of $5 \mathrm{~Hz}$, and 256 lines per frame. It was originally intended that six patches be scribed, but the stage movement in the $y$ direction did not work properly with the result that the two rows of patches overlapped each other. The incomplete overlap can be seen in the images. over the surface more than once in some regions of the patch as the surface was scribed.

In this letter we have only presented patterns scribed in the presence of $\mathrm{CF}_{3}\left(\mathrm{CF}_{2}\right)_{7} \mathrm{CH}=\mathrm{CH}_{2}$. However, we have also produced similar AFM and SEM results when using this procedure to functionalize and pattern surfaces with $\mathrm{CH}_{3}\left(\mathrm{CH}_{2}\right)_{13} \mathrm{CH}=\mathrm{CH}_{2}$ and $\mathrm{CH}_{3}\left(\mathrm{CH}_{2}\right)_{6} \mathrm{CH}_{2} \mathrm{OH}$. A significant issue requiring further study is the effect of tip size variation on feature size. Tip size variation can result from the tip manufacturing process or from wear during use. There was no evidence of wear in writing the sets of lines shown in Fig. 1; i.e., we were able to repeat the set and achieve the same linewidths. Extended writing, particularly at larger forces, does result in tip wear and yields larger lines. For example, after writing 20 patches $(10 \mu \mathrm{m} \times 10 \mu \mathrm{m}$ at $14 \mu \mathrm{N}$ vertical force) at we saw linewidths, written at $100 \mu \mathrm{N}$ of force, increase from $110 \mathrm{~nm}$ to $250 \mathrm{~nm}$.

The data presented in this work are consistent with the production of functionalized features on hydrogenterminated silicon by scribing it with an AFM tip. Because of the control AFM provides over tip force and direction, precisely defined feature sizes and shapes can be created. We expect that all of the chemistry that has previously been developed in macroscopic scribing studies will be applicable. We have extended chemomechanical patterning to the AFM; where small probes $(<10 \mathrm{~nm})$ and micronewton down to piconewton forces can be applied to strain or break a small number of chemical bonds. Although patterning with an AFM tip is slow, combining this approach with parallel AFM tip operation ${ }^{16}$ could allow large areas to be patterned rapidly. AFM based chemomechanical patterning is truly a molecular scale technology that will enable many nano- and bioapplications.

${ }^{1}$ J. Liu, M. J. Casavant, M. Cox, D. A. Walters, P. Boul, Wei Lu, A. J. Rimberg, K. A. Smith, D. T. Colbert, and R. E. Smalley, Chem. Phys. Lett. 303, 125 (1999).

${ }^{2}$ S. L. Brandow, M. S. Chen, T. Wang, C. S. Dulcey, J. M. Calvert, J. F. Bohland, G. S. Calabrese, and W. J. Dressick, J. Electrochem. Soc. 144, 3425 (1997).

${ }^{3}$ T. Vossmeyer, S. Jia, E. Delonno, M. R. Diehl, S.-H. Kim, X. Peng, A. P. Alvisatos, and J. R. Heath, J. Appl. Phys. 84, 3664 (1998).

${ }^{4}$ C. D. James, R. C. Davis, M. Meyer, A. Perez, S. Turner, L. Withers, L. Kam, G. L. Banker, H. G. Craighead, M. Isaacson, J. N. Turner, and W. Shain, IEEE Trans. Biomed. Eng. 47, 17 (2000).

${ }^{5}$ C. K. Harnett, K. M. Saryalakshmi, and H. G. Craighead, Langmuir 17, 178 (2001).

${ }^{6}$ D. Wang, S. G. Thomas, K. L. Wang, Y. Xia, and G. M. Whitesides, Appl. Phys. Lett. 70, 1593 (1997).

${ }^{7}$ T. L. Niederhauser, Y. Y. Lua, G. Jiang, S. D. Davis, D. A. Hess, and M. R. Linford, Angew. Chem. Int. Ed. Engl. 41, 2353-2356 (2002).

${ }^{8}$ Y. Y. Lua, T. L. Niederhauser, B. A. Wacaser, I. Mowat, A. T. Woolley, R. C. Davis, H. A. Fishman, and M. R. Linford, Langmuir (to be published).

${ }^{9}$ N. L. Abbot, J. P. Folkers, and G. M. Whitesides, Science 257, 1380 (1992).

${ }^{10}$ R. D. Piner, J. Zhu, F. Xu, S. Hong, and C. A. Mirkin, Science 283, 661 (1999).

${ }^{11}$ S. Xu and G.-Y. Liu, Langmuir 13, 127 (1997).

${ }^{12}$ M. Ara, H. Graaf, and H. Tada, Appl. Phys. Lett. 80, 2565 (2002).

${ }^{13}$ H. T. Lee, J. S. Oh, S.-J. Park, K.-H. Park, J. S. Ha, H. J. Yoo, and J.-Y. Koo, J. Vac. Sci. Technol. A 15, 1451 (1997).

${ }^{14}$ H. Sakaue, S. Fujiwara, S. Shingubara, and T. Takahagi, Appl. Phys. Lett. 78, 309 (2001).

${ }^{15}$ C. T. Gibson, G. S. Watson, and S. Myhra, Scanning 19, 564 (1997).

${ }^{16}$ D. Sarid, Scanning Force Microscopy: With Applications to Electric, Magnetic and Atomic Forces, Rev. ed. (Oxford University Press, New York, 1994), Chap. 1, pp. 5-17. 